\title{
Management of hypersensivity pneumonitis
}

Ioana $O$ Agache ${ }^{1,2^{*}}$ and Liliana Rogozea ${ }^{3}$

\begin{abstract}
Hypersensitivity pneumonitis (HP) is an interstitial lung disease due to a combined type III and IV reaction with a granulomatous inflammation, caused by cytotoxic delayed hypersensitivity lymphocytes, in a Th1/Th17 milieu, chaperoned by a deficient suppressor function of T regulatory cells. Skewing toward a Th2 phenotype is reported for chronic HP. Phenotypic expression and severity depends on environmental and/or host genetic and immune co-factors. The wide spectrum of causative antigens is continuously up-dated with new sources of airborne organic particles and drug-induced HP. The diagnosis requires a detailed history, measurement of environmental exposure, pulmonary function tests, imaging, detection of serum specific antibodies, broncho-alveolar lavage, antigen-induced lymphocyte proliferation, environmental or laboratory-controlled inhalation challenge and lung biopsy. Complete antigen avoidance is the best therapeutic measure, although very difficult to achieve in some cases. Systemic steroids are of value for subacute and chronic forms of $\mathrm{HP}$, but do not influence long term outcome. Manipulation of the immune response in HP holds future promise.
\end{abstract}

Keywords: Hypersensitivity pneumonitis, Interstitial lung disease, Lung immune response, Drug-induced lung disease, Granulomatous inflammation

\section{Introduction}

Hypersensitivity pneumonitis (HP) is an interstitial lung disease (ILD) due to a combined type III and IV reaction with a granulomatous inflammation. The formation of immune complexes with IgG was considered to be a central part of pathogenesis. The current view is that HP is caused by cytotoxic delayed hypersensitivity lymphocytes, in a Th1/Th17 milieu (Figure 1).

Although many individuals are exposed to environmental antigens known to induce HP only approximately 5-15\% will develop the disease [1]. The low prevalence rate suggests that the phenotypic expression of the disease depends on environmental co-factors, such as viruses $[2,3]$ and/or host genetic and immune co-factors, which also promote considerable variability in disease severity and response to treatment. The mechanisms of progression to a chronic form remain unclear. For chronic HP a skewing toward a Th2 phenotype was described $[4,5]$.

$\mathrm{HP}$ can occur in an occupational setting or after home exposure, following inhalation of organic antigens [mammalian and avian proteins, fungi, bacteria], low-molecular-weight chemicals or Mycobacterium aviumintracellulare complex organisms. As a non-inhalant variant HP can appear as a manifestation of drug-induced lung disease.

\section{Recently described entities}

There is a wide spectrum of causative antigens for HP, and new sources of airborne organic particles are continually being recognized. Recently described are the trombone player and Chacinero's lung [6,7], HP associated with catechin-rich green tea extracts [8], use of ultrasonic misting fountains at home [9], Shiitake mushroom spores [10], mosquito-coil smoke [11] medium-density fiberboard [12] or cash handling [13].

Reports on drug-induced HP are increasing in frequency, and interestingly some of these drugs were previously proposed as potential therapeutic agents for HP. Most of the recent reported drugs inducing $\mathrm{HP}$ are immune modulators used to treat neoplastic $[14,15]$ and connective tissue diseases [16] or transplant recipients $[17,18]$.

\footnotetext{
* Correspondence: ibrumaru@unitbv.ro

${ }^{1}$ Theramed Medical Center, Spatarul Luca Arbore 16, Brasov 500112, Romania

${ }^{2}$ Faculty of Medicine, Transylvania University Brasov, Department of Allergy and Clinical Immunology, Brasov 500112, Romania

Full list of author information is available at the end of the article
}

(C) 2013 Agache and Rogozea; licensee BioMed Central Ltd. This is an Open Access article distributed under the terms of the Creative Commons Attribution License (http://creativecommons.org/licenses/by/2.0), which permits unrestricted use, distribution, and reproduction in any medium, provided the original work is properly cited. 


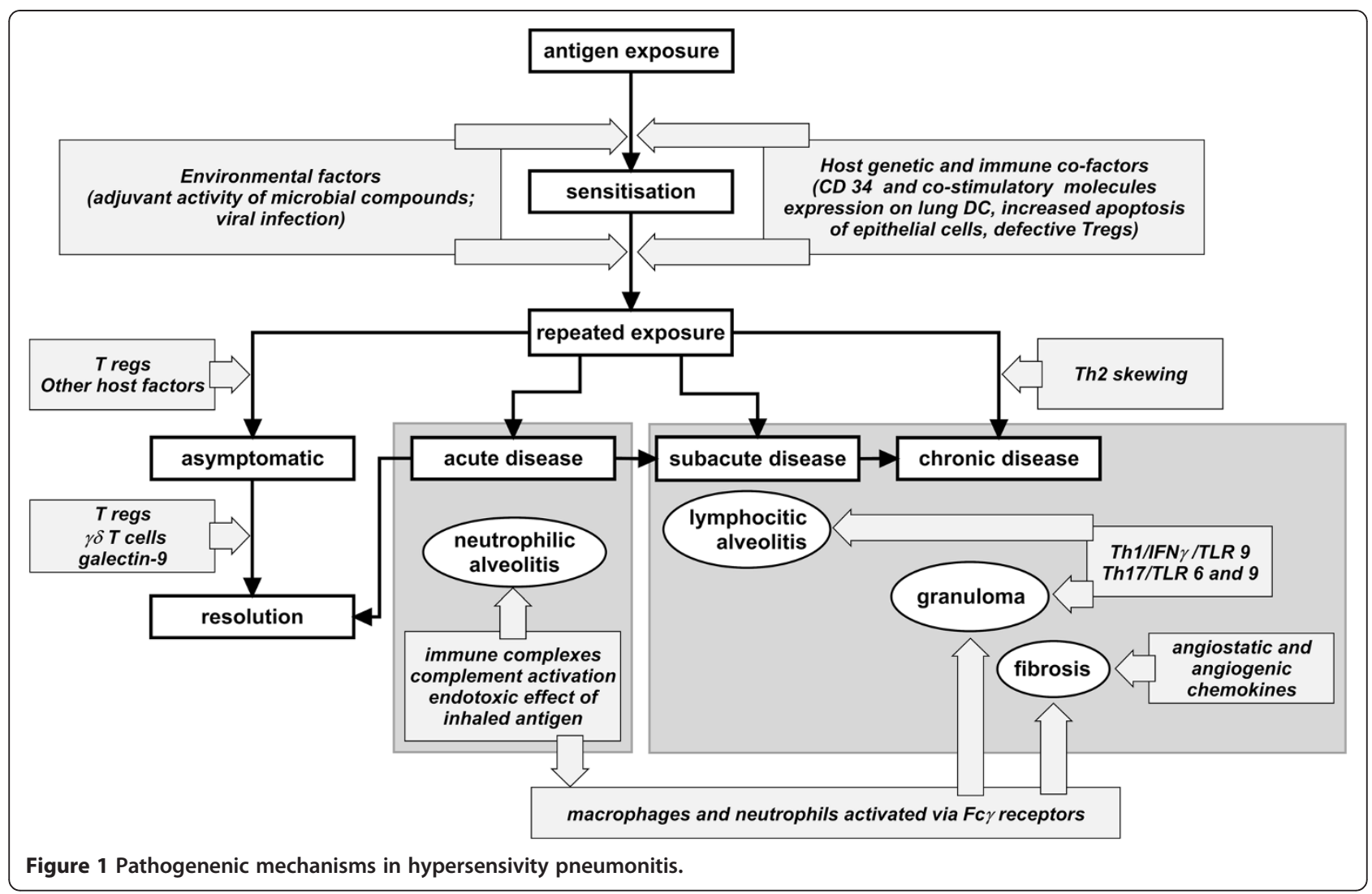

\section{Pathogenetic mechanisms relevant for future forms of therapy}

a. The role of antigen-presenting cells

Through their key role in antigen presentation dendritic cells (DCs) are key players in the development of $\mathrm{T}$ cell-dependent adaptive immune responses. In an animal model of HP expression of stem cell antigen CD34 by lung mucosal DCs was required for migration of DCs from the lung to the lymph nodes in response to the HP antigen Saccharopolyspora rectivirgula. Loss of CD34 protected from development of HP. Since the CD34 molecule seems to play a role in the transition from a primary to a chronic T-cell response in HP and its deletion in mice did not associate any significant defect it might represent an appealing future therapeutic target in HP [19]. Another requirement for an efficient antigen presenting cell (APC) is the presence of adjuvant activity of the microbial components. IL-1 level is increased in the bronchoalveolar lavage fluid (BALF) of HP patients [20]. In mice models IL-1 $\beta$ demonstrated adjuvant properties [21], and was necessary for the production of antibodies against T-cell dependent antigens [22]. IL$1 \beta$ acts directly on memory T Cells [21] and on CD4
T cells to enhance their antigen driven expansion and differentiation, especially into IL-17 and IL-4 producing cells [23]. Viral infection can also promote maturation of DCs [3].

HP is characterized by an influx of activated T cells to the lung, in which the CD28/B7 co-stimulatory signals from the APCs are essential for T cell activation and the outcome of the inflammatory response. The alveolar macrophages isolated from patients with HP have elevated levels of the co-stimulatory molecules CD80 and CD86 [24], while blockade of the CD80/86-CD28 co-stimulation pathway confers protection from experimental HP [25].

b. The role of T-cells

Interferon gamma [IFN- $\gamma$ ] plays a critical role in the formation of granuloma in HP, while TLR9 appears also required [26,27]. Overproduction of other Th1 cytokines, IL-12 and IL-18 by BALF macrophages was reported [28]. Other studies using animal models have suggested that HP is a Th17 disease calling into question the role of Th1 skewed response [29]. Genetic deletion and immunoneutralization of IL-17 protects against the development of mouse HP [30]. TLR9 is required for the development of Th17mediated granulomatous inflammation [31]. Within 
the Th17 inflammatory milieu TLR6 plays a pivotal role in the development and severity of HP via its role in IL-17A production [32]. A recent study showed that initially IFN- $\gamma$ production is dependent on IL-18 and the transcription factor T-bet, however as the disease continues IFN- $\gamma$ production becomes IL-18-independent and partially T-bet dependent. In animal models for HP T-bet deficiency leads to a more severe disease characterized by an exacerbated Th17 cell response, decreased Th1 cell response, and increased collagen production in the lung. T-betmediated protection does not appear to be due to the development of a protective Th1 response because shifting the balance from a Th17 predominant response to a Th1 response by inhibition of IL- 6 also results in lung pathology. Thus, both Th1 and Th17 cells can be pathogenic in HP, but they have divergent roles in the disease process [33]. In a mouse model of HP that progresses to lung fibrosis upon repeated exposure to Bacillus subtilis, $\gamma \delta$ T cells expand in the lung and inhibit collagen deposition. In this model a subset of $\gamma \delta$ cells are the predominant source of the Th17 cytokine IL-22. Blockade of expression of IL-22 accelerated lung fibrosis, whereas administration of recombinant IL22 inhibited lung fibrosis. Moreover, the presence of protective $\gamma \delta$ T cells and IL-22 diminished recruitment of CD4+ T cells to lung [34]. In the same model In the absence of IL-17 receptor signaling mice had delayed clearance of Bacillus subtilis with increased lung inflammation and fibrosis. Although IL-17A was predominantly expressed by $\gamma \delta \mathrm{T}$ cells, a compensatory increase in IL-17A expression by CD4[+] T cells was seen in the absence of $\gamma \delta$ T cells that resulted in similar levels of IL-17A in the lungs in TCR $\delta$ deficient mice [35]. Galectin-9 was also proven to expand the immunosupressive macrophages and ameliorate experimental Th1/Th17 cell-mediated HP [36]. Loss of T-regulatory cells (Tregs) control over the immune response is essential for the impaired immune tolerance in HP. Experimental HP induced in CD4 + CD25+ Tregs-depleted mice showed a protective role of Tregs via suppression of IFN $-\gamma$ production by $\mathrm{T}$ cells [37]. In humans $\mathrm{T}$ regs from BALF and blood obtained from asymptomatic exposed subjects had lower suppressive function compared to normal subjects, while Tregs from HP patients were totally nonfunctional and unable to suppress proliferation. Partially preserved Tregs suppressive function may explain antigen tolerance in asymptomatic exposed subjects. Defective Tregs function is potentially caused by increased IL-17 production since low levels of IL-17 were detected in sera and BALF from both normal and asymptomatic individuals, whereas measurable levels were found in HP patients [38].

c. The role of inflammation and apoptosis Macrophages and neutrophils are activated in HP via Fc $-\gamma$ receptors and accumulate in involved tissues [39]. Activated neutrophils loaded with matrix metalloproteinase 9 and collagenase- 2 were found to play role in lung damage and fibrotic response in chronic HP [40]. In addition, angiostatic and angiogenic chemokines promote the development of fibrosis [41,42].

Increased apoptosis in non-hematopoietic cells and Gr-1+ granulocytes of the lungs promotes HP by enhancing maturation and chemokine production of CD11c + DC [43]. Immunohistochemical studies of surgical lung specimens from HP patients showed up-regulation on epithelial cells of Fas, Fas ligand, p53 and p21 expression in usual interstitial pneumonia (UIP)-like lesions compared with nonspecific interstitial pneumonia (NSIP)-like lesions. The expression of p53 and p21 was also increased in fibrotic NSIP [fNSIP]-like lesions compared with normal lung tissues [44].

\section{Diagnostic procedures}

At the current time, there is no single diagnostic single procedure or biomarker to confirm the diagnosis of HP. The diagnosis requires a detailed and careful history that would include social, environmental, and occupational status, measurement of environmental exposure, pulmonary function tests, imaging, detection of serum specific antibodies, examination of BALF, antigen-induced lymphocyte proliferation, environmental or laboratory-controlled inhalation challenge with the suspected antigen and lung biopsy (Figure 2). Major and minor diagnostic criteria are described [45]. A sentinel case should prompt to the identification of exposed subjects who might develop the disease. Improvement of symptoms away from exposure and/or a rapid response to oral steroids should heighten the awareness of HP.

\section{a. Environmental exposure}

Recognition of the exposure to antigen is critical for diagnosis and avoidance of exposure. The detection of a single causative antigen for HP can prove very difficult since usually subjects are exposed to several inhalation antigens.

For bird fancier's lung (BFL) a variety of indirect and/ or unrecognized exposures to birds were described including pigeons raised by neighbors, a flock of pigeons and/or wild birds in parks, shrines and railway stations [46,47]. In addition avian antigen was reported to persist in the patient's house 6 months 


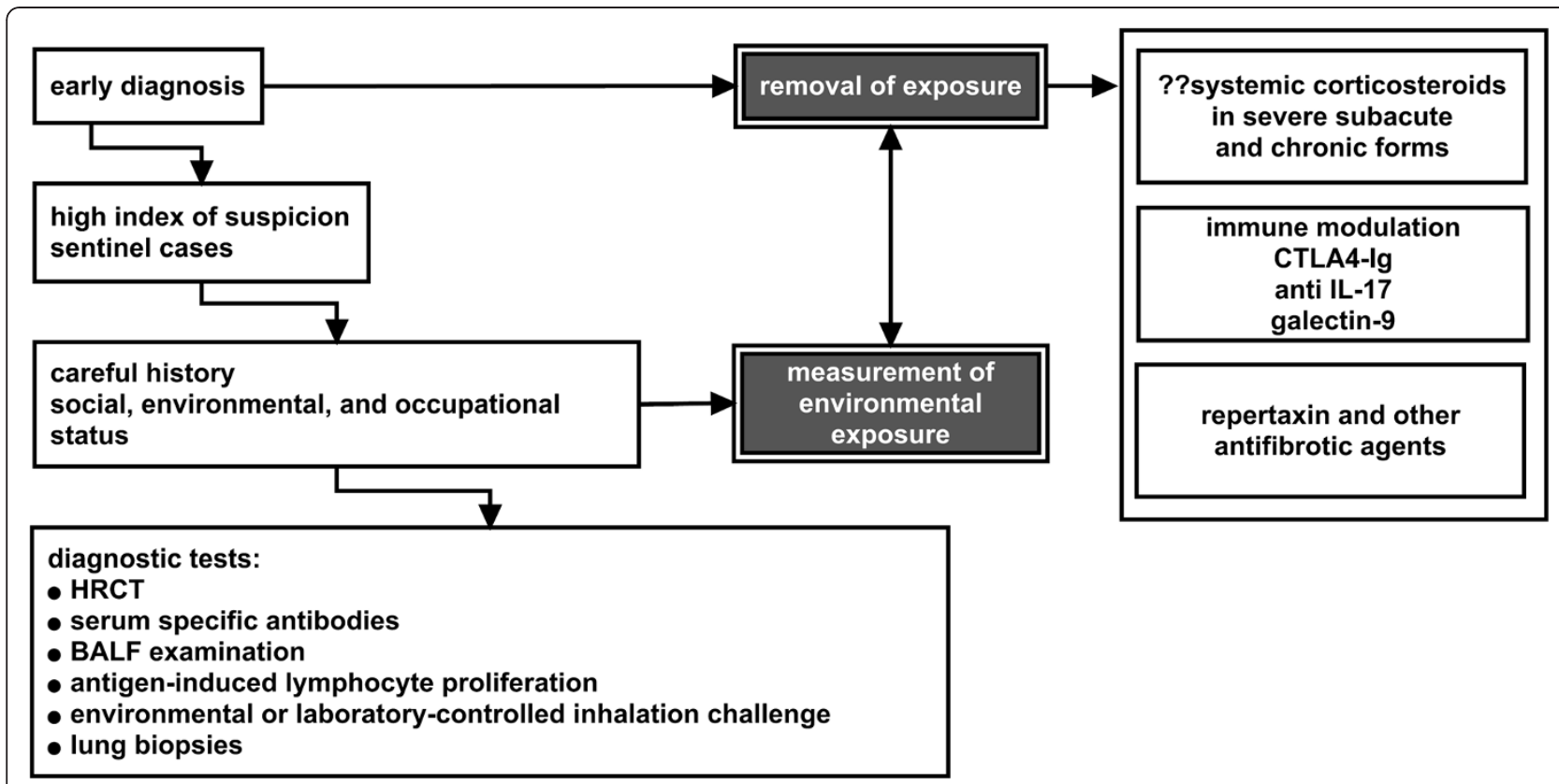

Figure 2 Management of hypersensivity pneumonitis.

after removal of all birds and environmental

cleanup [48].

Measuring the smallest amount of causative antigen

in patient's environment is crucial. For BFL the

methods used to detect the avian antigen in dust samples (inhibition ELISA) [48], or in dust and air samples (direct competitive ELISA) [49], were not sensitive enough to measure a small amount of antigen. Kuramochi et al. recently described an antigen-capture ELISA with signal amplification using catalyzed reporter deposition for measuring small amounts of indoor and outdoor avian antigen [50]. Molecular methods using quantitative polymerase-chain reaction might offer advantages over culture and optical methods for estimating low level exposure to microbiological agents such as fungi [51-53].

Evaluation of personal exposure at work should include details on current and previous occupations, work processes, type of exposure and environmental factors. In farmer's lung disease (FLD) both environmental factors and agricultural practices can independently modify concentrations in hay of microorganisms potentially responsible for HP. Bad climatic conditions of harvest, high-density haypacking modes, (especially round balls) and altitude (700-900 m) were associated with high concentrations of microorganisms in hay [54]. Worksite assessment together with an industrial hygienist is recommended. b. Imaging

High resolution computed tomography (HRCT) is the "gold-standard" imaging method for HP.

Although the individual HRCT findings are nonspecific, their combination coupled with their distribution can narrow the differential diagnosis. There are corresponding findings for each of the clinical phases of HP, although there is some overlap between the phases. Typical findings include confluent opacities in the acute phase, centrilobular nodules, areas of ground-glass attenuation, a mosaic perfusion pattern, air trapping in the subacute phase and subpleural irregular linear opacities with associated architectural distortion in the chronic phase. The reticulation HP can be random or have a predominantly subpleural and peri-bronchovascular distribution. Honeycombing may be present. In the acute and subacute phases, the disease is predominantly in the lower lungs, whereas in chronic $\mathrm{HP}$ the findings are predominant in the mid to upper lungs [55].

HRCT can be normal, especially when scans are obtained at greater intervals in relation to exposure [56].

c. Serum specific antibodies

The finding of circulating antibodies against the putative offending antigens is useful for diagnosis. However, it is important to emphasize that exposed individuals may have antibodies without disease, and some patients may give false negative results [57], 
diagnostic panels are usually incomplete and lab techniques may be insensitive to detect low levels of antibodies. Enzyme immunoassays (EIA) have successfully replaced in many cases the precipitation techniques. However, standardising EIA proves challenging because of the difficulty in obtaining stable solid phases from a huge variety of heterogeneous antigenic sources. Novel detection methods such as the automated fluorimetric EIA (Streptavidin ImmunoCAP) have been advocated for measuring antibodies elicited by protein antigens that are not commercially available [58]. The method can also differentiate with a specificity of $97 \%$ and a sensitivity of $90 \%$ between IgG antibodies specific for feather duvet lung (FDL) and IgG specific for BFL [59]. The use of recombinant antigens was reported for serological diagnosis of metalworking fluidassociated HP (MWF-HP) [60].

Choosing the relevant antigens for the EIA detection panel is essential. Out of the three Eurotium amstelodami antigens extracts tested (ascospore, conidia and hyphae), the cutoffs showed the highest sensitivity and specificity for the ascospore antigen, thus its measurement improves significantly the serological diagnosis of FLD [61]. Instead of using a standard kit the selection of antigens to be tested is better determined locally according to the prevalent antigens [62].

The sensitivity and specificity of serologic tests varies with the clinical form of the disease. For example, in acute BFL antibodies titers were markedly increased and showed high sensitivity and specificity ranging from $75-100 \%$, while in the chronic form antibody reactivity was slightly increased, showing a sensitivity of $27-73 \%$ and specificity of $45-100 \%$ [63].

The discriminative value of serologic tests between exposure and disease is controversial, and might vary with the putative antigen and with the detection method. One study showed no difference between HP patients and exposed controls for serum concentrations of IgG against moulds or mammals antigens [64]. However, in the same study IgG against bird antigens were significantly higher in HP patients versus exposed controls. In contrast, an older study using an immunoprecipitation method reported an incidence of $40 \%$ for specific IgG in asymptomatic bird keepers [65]. A threshold was proposed to discriminate between exposed controls and MWF-HP, but this remains to be proven for other antigens [66]. For antibodies against molds electrosyneresis on cellulose acetate was suggested to discriminate best between active HP and other types of ILD [67], or between patients and healthy exposed farmers [68].
Whether antibodies measured in healthy exposed controls further predispose to full blown HP remains to be proven in longitudinal studies. It has been shown that patients who were exposed to avian inhalation antigens in their childhood or during later life may develop FDL after exposure to bedding filled with goose feathers [69].

d. Bronchoalveolar lavage fluid examination A normal BALF excludes HP diagnosis [70]. On the other hand asymptomatic exposed subjects can have a lymphocytic alveolitis, which is not part of a subclinical form of disease as proved by the longterm follow up of these individuals [65].

BALF examination in HP usually shows a lymphocytic alveolitis, classically with an increase of CD8+ lymphocytes and inversion of the CD4/CD8 ratio, associated with moderate neutrophilia, and mild eosinophilia and mastocytosis [70]. An increase in plasma cells, signs of macrophage and $\mathrm{T}$ cell activation, foamy macrophages or with cockade-like structures in their cytoplasm were also described [71-74]. Acute episodes of HP are associated with an influx of neutrophils lasting for up to 1 week. After this period, the cellular profile of the BALF returns to lymphocytic alveolitis.

Absence of a low CD4/CD8 ratio should not exclude HP diagnosis, since a recent study reported a low ratio in only $34 \%$ cases. The CD4/CD8 ratio was not different between forms, etiologies of HP, and time elapsed since last antigen exposure, but was higher in women [75].

Immunophenotyping of BALF cells might improve diagnostic accuracy and measure disease activity. Thus, for HP patients a higher proportion of CD8 + T-cytotoxic cells was described. For all ILD a positive association was found between the density of type I alveolar epithelial cells and FVC [76]. Increased expression of CD69, VLA-1 and decreased expression of CD28 on CD4+ cells and increased expression of HLA-DR on CD8+ cells was correlated with the extent of parenchymal involvement and decreased DLCO values [77].

The detection of fungal DNA in BALF cell pellets might prove an useful diagnostic tool [78]. Proteome analysis of BALF in chronic HP pinpointed several biomarkers which might distinguish between the UIP and ANSIP patterns [79].

e. Antigen-induced lymphocyte proliferation Antigen-induced lymphocyte proliferation can aid the diagnosis of insidious forms of HP. In FDL specific antibodies against avian antigens were positive only in the acute form of the disease, while antigen-induced lymphocyte proliferation in peripheral blood or BALF cells was positive in all the 
patients [80]. In chronic BFL specific antibodies against pigeon or budgerigar dropping extracts were positive in $87 \%$ of the recurrent form and $35 \%$ of the insidious cases, while antigen-induced lymphocyte proliferation was positive in more than $90 \%$ of both groups [46]. Antigen-induced lymphocyte proliferation is also useful in differentiating subjects with HP from asymptomatic exposure [81,82].

f. Environmental or laboratory-controlled inhalation challenge

The use of inhalation challenge tests for HP diagnosis is hampered by the lack of standardization for the inhalation protocol and for defining a positive response.

The reported diagnostic sensitivity of the test for BFL is $92 \%$, while specificity reaches $100 \%$ [83]. Inhalation challenge with avian dropping extracts in chronic BFL evaluated as positive or probable all patients further proven by a combination of diagnostic criteria, whereas all control subjects were evaluated as negative [84].

g. Lung biopsies Establishing the diagnosis of HP in the absence of lung biopsy is challenging and is heavily dependent on identification of a specific antigenic exposure. Examination of surgical lung biopsies in HP usually shows an airway-centered chronic interstitial pneumonia, a lymphocyte-rich chronic bronchiolitis, and poorly formed non-necrotizing granulomas distributed mainly within the peribronchiolar interstitium. Variable degrees of peribronchiolar fibrosis and hyperplasia of the bronchiolar epithelium are described. In some patients, granulomatous inflammation may be lacking, resulting in a histological appearance resembling NSIP [85]. Increased fibrin deposition and neutrophilic infiltrate suggests either acute HP or exacerbation of chronic HP [86]. Late-stage fibrotic HP closely mimics UIP or fNSIP, while cellular NSIP or organizing pneumonia patterns are rarely found [85,87]. Centrilobular fibrosis, often connecting to the perilobular areas in the appearance of "bridging fibrosis" in association with an UIP pattern is also suggestive for chronic HP [88]. Acute exacerbations of HP appear as diffuse alveolar damage or bronchiolitis obliterans organizing pneumonia superimposed upon the fibrosing interstitial pneumonia [89].

Immunohistochemical demonstration of the causative antigen in the lung tissue might prove valuable. For BFL immunohistochemistry using a polyclonal antibody against pigeon serum showed a predominant cytoplasmic immunostaining in multinucleated giant cells and histiocytes from lung granulomas [90]. Immunohistochemistry can identify microgranulomas in chronic HP following detection of cathepsin-K, a potent cysteine protease expressed at high levels in activated macrophages [91].

\section{Measuring HP activity}

An increase in alveolar NO following re-exposure in $\mathrm{HP}$ was described in a case-report [92] and deserves further investigation as a measure of disease activity in HP.

As biomarkers reflecting the lung injury/regeneration cycle substances derived from type II pneumocytes are potential candidates to monitor disease activity. Serum Krebs von den Lungen-6 mucin (KL-6) is elevated in $70-100 \%$ of patients with various ILDs, including HP [93]. Increase in serum level of surfactant protein D [SP-D] was also reported [94]. In a long term follow-up of a patient with BFL after removal of antigen exposure SP-D and KL-6 returned to normal in 8 and 18 months respectively, while DLCO improved slowly in parallel [95].

\section{Prognostic factors}

The long-term outcome (mean 14 years) of pulmonary function was evaluated in FLD patients compared to control farmers matched by age, sex, and smoking habits. The mean DLCO was on average with $12 \%$ lower in patients compared to controls. The mean maximum expiratory flow at $50 \%$ of vital capacity was also lower and airway obstruction was more common. Patients with recurrent episodes had a significantly lower mean DLCO compared to those experiencing only a single episode [96].

High BALF neutrophil count was documented to be a sign of irreversible lung fibrosis [32]. CA 15-3 was demonstrated equally sensitive and specific to KL-6 in terms of differentiating between ILDs with and without fibrosis [97].

As for other ILD the presence of established fibrosis, especially when associated with architectural distortion in the form of honeycombing, is associated with shorter survivals [98]. HRCT patterns, in particular, severity of traction bronchiectasis and extent of honeycombing are superior to FEV1, FVC and DLCO for predicting mortality in patients with chronic HP [99]. The prognosis of fNSIP pattern tends to be better compared to the UIP pattern [87]. Pulmonary hypertension is not rare in chronic HP and significantly impacts survival [100].

Patients with low total lung capacity and DLCO, low lymphocyte levels in BALF and a UIP-like pattern at the time of diagnosis have increased risk for acute exacerbations of chronic HP [101].

The $10.6 \%$ reported prevalence of lung cancer in chronic HP is similar to idiopathic pulmonary fibrosis (IPF). Tumors were located adjacent to honeycombing lesions, bullae or in the relatively normal lung [102]. 


\section{Treatment}

Complete antigen avoidance is the essential step in the management of HP (Figure 2). The majority of cases improve or heal, but some evolve to a chronic form probably due to persistence of exposure at an undetectable level in association with genetic and immunologic factors. In a long term follow-up of patients with BFL there was persistence of sensitized lymphocytes and antibody production in the respiratory tract up to 5 years [103].

Systemic corticosteroids are recommended for subacute and chronic forms of HP. The usual regimen consists of initial high doses followed by gradual tapering. Treatment continues until no further improvement in physiologic abnormalities is observed. The use of inhaled corticosteroids is anecdotal.

In a cohort of Danish children with HP high dose intravenous methylprednisolone had no clinical impact, since both lung function and DLCO remained subnormal [104]. In adults with FLD corticosteroid treatment improved quickly lung function compared to placebo, but after 5 years there was no difference between the two groups. An increased incidence of recurrent attacks, without reaching statistical significance, was observed in the corticosteroid group [105]. In adults with chronic HP prednisolone was effective in only $58 \%$ of cases [106], thus for progressive chronic HP immunosuppressants may be necessary.

Although in vitro studies have shown promise for thalidomide [107], pentoxifylline [108], low-dose long-term macrolides [109], and cyclosporine [110], no controlled clinical trials have been performed. In addition, several recent reports on HP induced by thalidomide-like drugs such as lenalidomide [111,112], roxytromycin [113], cyclosporin [114] and cyclosporin-like drugs such as everolimus [17] and sirolimus [18] preclude the use of these drugs for HP. Given the role of IFN- $\gamma$ in promoting granuloma formation in HP it cannot be an option as antifibrotic treatment as it is for IPF.

Manipulation of the immune response in HP holds future promise. In a HP experimental model mice treated with CTLA-4Ig showed a significant decrease in the extent of lung damage and in the number of BALF inflammatory cells, with diminished CD4/CD8 T cell ratio. A significant increase in the lung $\gamma \delta \mathrm{T}$ and NKT cells was observed after two weeks of CTLA-4Ig administration, while after 3 weeks an increased of regulatory T cells occurred [115]. Other potential targets for immune modulation in HP are Tbet, DCs and adjuvant factors, Th17, galectin-9, Tregs and activated cytotoxic T cells.

Reparixin (Repertaxin) ${ }^{\mathrm{TM}}$ (Dompe Farmaceutici S.p.A., Milan, Italy Product), an inhibitor of CXCR1 and CXCR2 activation, has been shown to attenuate inflammatory responses in various injury models $[116,117]$ and might prove useful in managing pulmonary fibrosis.

\section{Key-messages}

1. new antigens inducing HP are described every year for both home and work exposure

2. high index of suspicion for HP in cases with unexplained dyspnea and frequent monitoring of subjects at risk are essential for an early diagnosis

3. a set of complementary diagnostic tests should be used for diagnosis and to assess severity, disease activity and prognosis

4. environmental detection of antigen is essential for both diagnosis and further avoidance of exposure

5. future improvement of the serological diagnosis of HP needs a better inventory of etiologic agents with generation of local relevant diagnostic panels, the use of more efficient serological techniques, together with longitudinal evaluation of exposed subjects.

6. complete antigen avoidance is the best therapeutic measure, although very difficult to achieve in some cases

7. systemic steroids are of value for subacute and chronic forms of HP but do not influence long term outcome

8. novel anti-inflammatory, immunoregulatory, and antifibrotic treatments are urgently needed for subacute and chronic HP

\section{Abbreviations}

APC: Antigen presenting cells; BALF: Broncho-alveolar lavage fluid; BFL: Birdfancier lung; CTLA-4: Cytotoxic T-Lymphocyte Antigen 4; DCs: Dendritic cells; DLCO: Diffusing capacity; EIA: Enzyme immunoassays; FDL: Feather duvet lung; FEV1: Forced expiratory volume in the first second; FLD: Farmers' lung disease; fNSIP: Fibrotic nonspecific interstitial pneumonia; FVC: Forced vital capacity; HP: Hypersensitivity pneumonitis; HRCT: High resolution computed tomography; IFN-Y: Interferon gamma; Ig: Immunoglobulin; ILD: Interstitial lung disease; IPF: Idiopathic pulmonary fibrosis; KL-6: Serum Krebs von den Lungen-6 mucin; MWF-HP: Metalworking fluid-associated HP; NKT cells: Natural killer T cells; NO: Nitric oxide; NSIP: Nonspecific interstitial pneumonia; SP-D: Surfactant protein D; UIP: Usual interstitial pneumonia; Tregs: T regulatory cells.

\section{Competing interests}

The authors declare no competing interests relevant to this paper.

\section{Authors' contribution}

IA, LR both equally contributed to the manuscript. Both authors read and approved the final manuscript.

\section{Author details}

${ }^{1}$ Theramed Medical Center, Spatarul Luca Arbore 16, Brasov 500112 , Romania. ${ }^{2}$ Faculty of Medicine, Transylvania University Brasov, Department of Allergy and Clinical Immunology, Brasov 500112, Romania. ${ }^{3}$ Faculty of Medicine, Transylvania University Brasov, Department of Fundamental and Prophylactic Medical Science, Brasov 500112, Romania.

Received: 9 November 2012 Accepted: 1 February 2013

Published: 4 February 2013

\section{References}

1. Patel AM, Ryu JH, Reed CE: Hypersensitivity pneumonitis: current concepts and future questions. J Allergy Clin Immunol 2001, 108:661-670.

2. Cormier $Y$, Israël-Assayag E: The role of viruses in the pathogenesis of hypersensitivity pneumonitis. Curr Opin Pulm Med 2000, 6:420-423. 
3. Girard M, Israël-Assayag E, Cormier Y: Mature CD11c[+] cells are enhanced in hypersensitivity pneumonitis. Eur Respir J 2009, 34:749-756.

4. Barrera L, Mendoza F, Zuniga J, et al: Functional diversity of T-cell subpopulations in subacute and chronic hypersensitivity pneumonitis. Am J Respir Crit Care Med 2008, 177:44-55

5. Mitaka K, Miyazaki Y, Yasui M, et al: Th2-biased immune responses are important in a murine model of chronic hypersensitivity pneumonitis. Int Arch Allergy Immunol 2011, 154:264-274.

6. Metersky ML, Bean SB, Meyer JD, et al: Trombone player's lung: a probable new cause of hypersensitivity pneumonitis. Chest 2010, 138:754-756.

7. Morell F, Cruz MJ, Gómez FP, et al: Chacinero's lung - hypersensitivity pneumonitis due to dry sausage dust. Scand J Work Environ Health 2011, 37:349-356

8. Otera H, Tada K, Sakurai T, et al: Hypersensitivity pneumonitis associated with inhalation of catechin-rich green tea extracts. Respiration 2011, 82:388-392.

9. Koschel D, Stark W, Karmann F, et al: Extrinsic allergic alveolitis caused by misting fountains. Respir Med 2005, 99:943-947.

10. Ampere A, Delhaes L, Soots J, Bart F, Wallaert B: Hypersensitivity pneumonitis induced by Shiitake mushroom spores. Med Mycol 2012, 50:654-657.

11. Roshnee G, Cao GQ, Chen H: Hypersensitivity pneumonitis due to residential mosquito-coil smoke exposure. Chin Med J (Engl) 2011, 124:1915-1918.

12. Toribio R, Cruz MJ, Morell F, et al: Hypersensitivity pneumonitis related to medium-density fiberboard. Arch Bronconeumol 2012, 48:29-31.

13. Kupeli E, Karnak D, Sak SD, et al: Hazards of the 'hard cash': hypersensitivity pneumonitis. Can Respir J 2010, 17:e102-e105.

14. Usui K, Katou Y, Furushima K, et al: Interstitial lung disease during chemotherapy combined with oxaliplatin and/or bevacizumab in advanced colorectal cancer patients. Jph J Clin Oncol 2011, 41:498-502.

15. Tonelli AR, Lottenberg R, Allan RW, Sriram PS: Rituximab-induced hypersensitivity pneumonitis. Respiration 2009, 78:225-229.

16. Martin N, Innes JA, Lambert CM, et al: Hypersensitivity pneumonitis associated with leflunomide therapy. J Rheumatol 2007, 34:1934-1937.

17. Howard L, Gopalan D, Griffiths M, et al: Sirolimus-induced pulmonary hypersensitivity associated with a CD4 T-cell infiltrate. Chest 2006, 129:1718-1721.

18. Alexandru S, Ortiz A, Baldovi S, et al: Severe everolimus-associated pneumonitis in a renal transplant recipient. Nephrol Dial Transplant 2008, 23:3353-3355.

19. Blanchet MR, Bennett JL, Gold MJ, et al: CD34 is required for dendritic cell trafficking and pathology in murine hypersensitivity pneumonitis. Am J Respir Crit Care Med 2011, 184:687-698.

20. Reynolds SP, Jones KP, Edwards JH, Davies BH: Immunoregulatory proteins in bronchoalveolar lavage fluid. A comparative analysis of pigeon breeders' disease, sarcoidosis and idiopathic pulmonary fibrosis. Sarcoidosis 1989, 6:125-134.

21. Dinarello CA: The many worlds of reducing interleukin1. Arthritis Rheum 2005, 52:1960-1967.

22. Nakae $S$, Asano $M$, Horai $R$, Iwakura $Y$ : Interleukin1 beta, but not interleukin-1 alpha, is required for Tcell-dependent antibody production. Immunology 2001, 104:402-409.

23. Ben-Sasson SZ, Hu-Li J, Quiel J, et al: IL1 acts directly on CD4 T cells to enhance their antigen-driven expansion and differentiation. Proc Natl Acad Sci USA 2009, 106:7119-7124.

24. Israel-Assayag E, Dakhama A, et al: Expression of costimulatory molecules on alveolar macrophages in hypersensitivity pneumonitis. Am J Respir Crit Care Med 1999, 159:1830-1834.

25. Israel-Assayag E, Fournier M, Cormier Y: Blockade of T cell costimulation by CTLA4-Ig inhibits lung inflammation in murine hypersensitivity pneumonitis. J Immunol 1999, 163:6794-6799.

26. Gudmundsson G, Hunninghake GW: Interferon-gamma is necessary for the expression of hypersensitivity pneumonitis. J Clin Invest 1997, 99:2386-2390

27. Bhan U, Newstead MJ, Zeng X, et al: Stachybotrys chartarum-induced hypersensitivity pneumonitis is TLR9 dependent. Am J Pathol 2011, 179:2779-2787.

28. Ye Q, Nakamura S, Sarria R, et al: Interleukin 12, interleukin 18, and tumor necrosis factor alpha release by alveolar macrophages: acute and chronic hypersensitivity pneumonitis. Ann Allergy Asthma Immunol 2009, 102:149-154.
29. Simonian PL, Roark CL, Wehrmann F, et al: Th17-polarized immune response in a murine model of hypersensitivity pneumonitis and lung fibrosis. J Immunol 2009, 182:657-665.

30. Joshi AD, Fong DJ, Oak SR, et al: Interleukin-17-mediated immunopathogenesis in experimental hypersensitivity pneumonitis. Am J Respir Crit Care Med 2009, 179:705-716.

31. Bhan U, Newstead MJ, Zeng X, et al: J TLR9-Dependent IL-23/IL-17 Is Required for the Generation of Stachybotrys chartarum-Induced Hypersensitivity Pneumonitis. Immunol 2013, 190:349-356.

32. Fong DJ, Hogaboam CM, Matsuno $Y$, et al: Toll-like receptor 6 drives interleukin-17A expression during experimental hypersensitivity pneumonitis. Immunology 2010, 130:25-136.

33. Abdelsamed HA, Desai M, Nance SC, et al: T-bet controls severity of hypersensitivity pneumonitis. J Inflamm 2011, 8:15.

34. Simonian $\mathrm{PL}$, Wehrmann $\mathrm{F}$, Roark $\mathrm{CL}$, et al: $\gamma \delta \mathrm{T}$ cells protect against lung fibrosis via IL-22. J Exp Med 2010, 207:2239-2253.

35. Simonian PL, Roark CL, Wehrmann F, et al: IL-17A-expressing T cells are essential for bacterial clearance in a murine model of hypersensitivity pneumonitis. J Immunol 2009, 182:6540-6549.

36. Arikawa T, Saita N, Oomizu S, et al: Galectin-9 expands immunosuppressive macrophages to ameliorate T-cell-mediated lung inflammation. Eur J Immunol 2010, 40:548-558.

37. Park Y, Oh SJ, Chung DH: CD4 + CD25+ regulatory T cells attenuate hypersensitivity pneumonitis by suppressing IFN- $\gamma$ production by CD4 + and CD8+ T cells. J Leukoc Biol 2009, 86:1427-1437.

38. Girard M, Israël-Assayag E, Cormier Y: Impaired function of regulatory Tcells in hypersensitivity pneumonitis. Eur Respir J 2011, 37:632-639.

39. Park HJ, Kim HS, Chung DH: Fcgamma receptors modulate pulmonary inflammation by activating innate immune cells in murine hypersensitivity pneumonitis. Immune Netw. 2010, 10:26-34

40. Pardo A, Barrios R, Gaxiola M, et al: Increase of lung neutrophils in hypersensitivity pneumonitis is associated with lung fibrosis. Am J Respir Crit Care Med 2000, 161:1698-1704.

41. Cui A, Anhenn O, Theegarten D, et al: Angiogenic and angiostatic chemokines in idiopathic pulmonary fibrosis and granulomatous lung disease. Respiration 2010, 80:372-378.

42. Strieter RM, Belperio JA, Keane MP: CXC chemokines in angiogenesis related to pulmonary fibrosis. Chest 2002, 122:298-301S

43. Hwang SJ, Kim HS, Chung DH: Fas/Fas ligand-mediated apoptosis promotes hypersensitivity pneumonitis in mice by enhancing maturation of dendritic cells. Am J Respir Crit Care Med 2010, 181:1250-1261.

44. Jinta T, Miyazaki $Y$, Kishi M, et al: The pathogenesis of chronic hypersensitivity pneumonitis in common with idiopathic pulmonary fibrosis: Expression of apoptotic markers. Am J Clin Pathol 2010, 134:613-620.

45. Fink JN, Ortega HG, Reynolds HY, et al: NHLBI workshop: needs and opportunities for research in hypersensitivity pneumonitis. Am J Respir Crit Care Med 2005, 171:792-798.

46. Greinert U, Lepp U, Becker W: Bird keeper's lung without bird keeping. Eur J Med Res 2000, 27:124

47. Saltoun CA, Harris KE, Mathisen TL, et al: Hypersensitivity pneumonitis resulting from community exposure to Canada goose droppings: when an external environmental antigen becomes an indoor environmental antigen. Ann Allergy Asthma Immunol 2000, 84:84-86.

48. Craig TJ, Hershey J, Engler RJ, et al: Bird antigen persistence in the home environment after removal of the bird. Ann Allergy 1992, 69:510-512

49. Curtis $L$, Lee $B S$, Cai $D$, et al: Pigeon allergens in indoor environments: a preliminary study. Allergy 2002, 57:627-631.

50. Kuramochi J, Inase N, Takayama K, et al: Detection of indoor and outdoor avian antigen in management of bird-related hypersensitivity pneumonitis. Allergol Int 2010, 59:223-228.

51. McDevitt JJ, Lees PS, Merz WG, et al: Development of a method to detect and quantify Aspergillus fumigatus conidia by quantitative PCR for environmental air samples. Mycopathologia 2004, 158:325-335.

52. Rhodes G, Fluri A, Ruefenacht A, et al: Implementation of a quantitative real-time PCR assay for the detection of Mycobacterium immunogenum in metalworking fluids. J Occup Environ Hyg 2011, 8:478-483.

53. Schäfer J, Kämpfer $P$, Jäckel U: Detection of Saccharopolyspora rectivirgula by quantitative real-time PCR. Ann Occup Hyg 2011, 55:612-619. 
54. Gbaguidi-Haore H, Roussel S, Reboux G, et al: Multilevel analysis of the impact of environmental factors and agricultural practices on the concentration in hay of microorganisms responsible for farmer's lung disease. Ann Agric Environ Med 2009, 16:219-225.

55. Silva Cl, Churg A, Müller NL: Hypersensitivity pneumonitis: spectrum of high-resolution CT and pathologic findings. Am J Roentgenol 2007, 188:334-344.

56. Lacasse $Y$, Selman M, Costabel U, et al: Clinical diagnosis of hypersensitivity pneumonitis. Am J Respir Crit Care Med 2003, 168:952-958.

57. Sennekamp J, Niese D, Stroehmann I, et al: Pigeon breeders' lung lacking detectable antibodies. Clin Allergy 1978, 8:305-310.

58. Rodrigo MJ, Postigo I, Wangensteen O, et al: A new application of Streptavidin ImmunoCAP for measuring IgG antibodies against non-available commercial antigens. Clin Chim Acta 2010, 411:1675-1678.

59. Koschel D, Lützkendorf $L$, Wiedemann B, et al: Antigen-specific lgG antibodies in feather duvet lung. Eur J Clin Investig 2010, 40:797-802.

60. Roussel S, Rognon B, Barrera C, et al: Immuno-reactive proteins from Mycobacterium immunogenum useful for serodiagnosis of metalworking fluid hypersensitivity pneumonitis. Int J Med Microbiol 2011, 301:150-156.

61. Roussel S, Reboux G, Rognon B, et al: Comparison of three antigenic extracts of Eurotium amstelodami in serological diagnosis of farmer's lung disease. Clin Vaccine Immunol 2010, 17:160-167.

62. Reboux G, Piarroux R, Mauny F, et al: Role of molds in farmer's lung disease in eastern France. Am J Respir Crit Care Med 2001, 163:1534-1539.

63. Inase N, Unoura K, Miyazaki Y, et al: Measurement of bird specific antibody in bird-related hypersensitivity pneumonitis. Nihon Kokyuki Gakkai Zasshi 2011, 49:717-722.

64. Sterclova M, Vasakova M, Metlicka M: Significance of specific lgG against sensitizing antigens in extrinsic allergic alveolitis: serological methods in EAA. Rev Port Pneumol 2011, 17:253-259.

65. Fink JN, Schlueter DP, Sosman AJ, et al: Clinical survey of pigeon breeders. Chest 1972, 62:277-281.

66. Tillie-Leblond I, Grenouillet F, Reboux G, et al: Hypersensitivity pneumonitis and metalworking fluids contaminated by mycobacteria. Eur Respir J 2011, 37:640-647.

67. Fenoglio CM, Reboux G, Sudre B, et al: Diagnostic value of serum precipitins to mould antigens in active hypersensitivity pneumonitis. Eur Respir J 2007, 29:706-712

68. Reboux G, Piarroux R, Roussel S, et al: Assessment of four serological techniques in the immunological diagnosis of farmers' lung disease. J Med Microbiol 2007, 56:1317-1321.

69. Inase N, Sakashita H, Ohtani $Y$, et al: Chronic bird fancier's lung presenting with acute exacerbation due to use of a feather duvet. Intern Med 2004 43:835-857.

70. Cordeiro CR, Jones JC, Alfaro T, et al: Bronchoalveolar lavage in occupational lung diseases. Semin Respir Crit Care Med 2007, 28:504-513.

71. Cormier $Y$, Letourneau L, Racine G: Significance of precipitins and asymptomatic lymphocytic alveolitis: a 20-yr follow-up. Eur Respir J 2004 23:523-525

72. Drent M, Wagenaar S, van Velzen-Blad H, et al: Relationship between plasma cell levels and profile of bronchoalveolar lavage fluid in patients with subacute extrinsic allergic alveolitis. Thorax 1993 , 48:835-839

73. Costabel U, Bross KJ, Ruhle KH, et al: la-like antigens on T-cells and their subpopulations in pulmonary sarcoidosis and in hypersensitivity pneumonitis. Analysis of bronchoalveolar and blood lymphocytes. Am Rev Respir Dis 1985, 131:337-342.

74. Uzaslan E, Guzman J, Costabel U: Cockade-like structures in alveolar macrophages in extrinsic allergic alveolitis. Respiration 2005, 72:46-51.

75. Caillaud DM, Vergnon JM, Madroszyk A, et al: Bronchoalveolar lavage in hypersensitivity pneumonitis: a series of 139 patients. Inflamm Allergy Drug Targets 2012, 11:15-19.

76. Capelozzi VL, Faludi EP, Balthazar AB, et al: Bronchoalveolar lavage improves diagnostic accuracy in patients with diffuse lung disease. Diagn Cytopathol 2013, 41:1-8.

77. Heron M, Claessen AM, Grutters JC, et al: T-cell activation profiles in different granulomatous interstitial lung diseases-a role for CD8 + CD28 [null] cells? Clin Exp Immunol 2010, 160:256-265.
78. Unoura K, Miyazaki Y, Sumi Y, et al: Identification of fungal DNA in BALF from patients with home-related hypersensitivity pneumonitis. Respir Med 2011, 105:1696-1703.

79. Okamoto T, Miyazaki Y, Shirahama R, et al: Proteome analysis of bronchoalveolar lavage fluid in chronic hypersensitivity pneumonitis. Allergol Int 2012, 61:83-92.

80. Inase N, Ohtani Y, Sumi Y, et al: A clinical study of hypersensitivity pneumonitis presumably caused by feather duvets. Ann Allergy Asthma Immunol 2006, 96:98-104.

81. Bouic PJ, Nel NC, Beer PM, et al: In vitro reactivities of blood lymphocytes from symptomatic and asymptomatic pigeon breeders to antigen and mitogens. Int Arch Allergy Appl Immunol 1989, 89:222-228.

82. Hansen PJ, Penny R: Pigeon breeder's disease: study of the cell-mediated immune response to pigeon antigens by the lymphocyte culture technique. Int Arch Allergy Appl Immunol 1974, 47:498-507.

83. Morell F, Roger A, Reyes L, et al: Bird fancier's lung: a series of 86 patients. Medicine [Baltimore]. 2008, 87:110-130.

84. Ohtani Y, Kojima K, Sumi $Y$, et al: Inhalation provocation tests in chronic bird fancier's lung. Chest 2000, 118:1382-1389.

85. Myers $\mathrm{J}$ : Hypersensitivity pneumonia: the role of lung biopsy in diagnosis and management. Mod Pathol 2012, 25(Suppl 1):S58-S67.

86. Hariri LP, Mino-Kenudson M, Shea B, et al: Distinct histopathology of acute onset or abrupt exacerbation of hypersensitivity pneumonitis. Hum Pathol 2012, 43:660-668.

87. Ohtani $Y$, Saiki S, Kitaichi M, et al: Chronic bird fancier's lung: histopathological and clinical correlation. An application of the 2002 ATS/ERS consensus classification of the idiopathic interstitial pneumonias. Thorax 2005, 60:665-671.

88. Akashi T, Takemura T, Ando N, et al: Histopathologic analysis of sixteen autopsy cases of chronic hypersensitivity pneumonitis and comparison with idiopathic pulmonary fibrosis/usual interstitial pneumonia. Am J Clin Pathol 2009, 131:405-415.

89. Churg A, Wright JL, Tazelaar HD: Acute exacerbations of fibrotic interstitial lung disease. Histopathology 2011, 58:525-530.

90. León DE, Retana VN, Hernández-Pando R, et al: Pigeon hypersensitivity pneumonitis: immunohistochemical demonstration of the causative antigen in the lung. Prim Care Respir J 2007, 16:252-256.

91. Reghellin D, Poletti $V$, Tomassetti $S$, et al: Cathepsin- $K$ is a sensitive immunohistochemical marker for detection of micro-granulomas in hypersensitivity pneumonitis. Sarcoidosis Vasc Diffuse Lung Dis 2010, 27:57-63.

92. Shirai T, Ikeda M, Morita S, et al: Elevated alveolar nitric oxide concentration after environmental challenge in hypersensitivity pneumonitis. Respirology 2010, 15:721-722.

93. Ishikawa N, Hattori N, Yokoyama A, et al: Utility of KL-6/MUC1 in the clinical management of interstitial lung diseases. Respir Investig 2012 50:3-13.

94. Inase N, Ohtani $Y$, Usui $Y$, et al: Chronic summer-type hypersensitivity pneumonitis: clinical similarities to idiopathic pulmonary fibrosis. Sarcoidosis Vasc Diffuse Lung Dis 2007, 24:141-147.

95. Takao T, Hanehira $T$, Zenke $Y$, et al: The sequential changes of the serum levels of KL-6, SP-D, and DLco were followed for a long term in a case of acute bird fancier's lung. Aerugi 2009, 58:1433-1440.

96. Erkinjuntti-Pekkanen R, Kokkarinen II, Tukiainen $\mathrm{HO}$, et al: Long-term outcome of pulmonary function in farmer's lung: a 14 year follow-up with matched controls. Eur Respir J 1997, 10:2046-2050.

97. Kruit A, Gerritsen WB, Pot N, et al: CA 15-3 as an alternative marker for KL-6 in fibrotic lung diseases. Sarcoidosis Vasc Diffuse Lung Dis 2010, 27:138-146.

98. Tateishi T, Ohtani Y, Takemura T, et al: Serial high-resolution computed tomography findings of acute and chronic hypersensitivity pneumonitis induced by avian antigen. J Comput Assist Tomogr 2011, 35:272-279.

99. Walsh SL, Sverzellati N, Devaraj A, Wells AU, Hansell DM: Chronic hypersensitivity pneumonitis: high resolution computed tomography patterns and pulmonary function indices as prognostic determinants. Eur Radiol 2012, 22:1672-1679.

100. Koschel DS, Cardoso C, Wiedemann B, et al: Pulmonary hypertension in chronic hypersensitivity pneumonitis. Lung 2012, 190:295-302. 
101. Miyazaki Y, Tateishi T, Akashi T, et al: Clinical predictors and histologic appearance of acute exacerbations in chronic hypersensitivity pneumonitis. Chest 2008, 134:1265-1270.

102. Kuramochi J, Inase N, Miyazaki Y, et al: Lung cancer in chronic hypersensitivity pneumonitis. Respiration 2011, 82:263-267.

103. Yoshizawa Y, Miyake S, Sumi Y, et al: A follow-up study of pulmonary function tests, bronchoalveolar lavage cells, and humoral and cellular immunity in bird fancier's lung. J Allergy Clin Immunol 1995, 96:122-129.

104. Buchvald F, Petersen BL, Damgaard K, et al: Frequency, treatment, and functional outcome in children with hypersensitivity pneumonitis. Pediatr Pulmonol 2011, 46:1098-1107.

105. Kokkarinen Jl, Tukiainen HO, Terho EO: Effect of corticosteroid treatment on the recovery of pulmonary function in farmer's lung. Am Rev Respir Dis 1992, 145:3-5

106. Yoshizawa Y, Ohtani Y, Hayakawa H, et al: Chronic hypersensitivity pneumonitis in Japan: a nationwide epidemiologic survey. J Allergy Clin Immunol 1999, 103:315-320.

107. Ye Q, Chen B, Tong Z, et al: Thalidomide reduces IL-18, IL-8 and TNFalpha release from alveolar macrophages in interstitial lung disease. Eur Respir J 2006, 28:824-831.

108. Tong Z, Chen B, Dai H, et al: Extrinsic allergic alveolitis: inhibitory effects of pentoxifylline on cytokine production by alveolar macrophages. Ann Allergy Asthma Immunol 2004, 92:234-239.

109. Miyajima M, Suga M, Nakagawa K, et al: Effects of erythromycin on experimental extrinsic allergic alveolitis. Clin Exp Allergy 1999, 29:253-261.

110. Losa García JE, Mateos Rodríquez F, Jiménez López A, et al: Effect of cyclosporin A on inflammatory cytokine production by human alveolar macrophages. Respir Med 1998, 92:722-728.

111. Thornburg A, Abonour R, Smith P, et al: Hypersensitivity pneumonitis-like syndrome associated with the use of lenalidomide. Chest 2007, 131:1572-1574.

112. Lerch E, Györik S, Feilchenfeldt J, et al: A case of lenalidomide-induced hypersensitivity pneumonitis. Onkologie 2010, 33:249-252.

113. Chew GY, Hawkins CA, Cherian M, et al: Roxithromycin induced hypersensitivity pneumonitis. Pathology 2006, 38:475-477.

114. Roelofs PM, Klinkhamer PJ, Gooszen HC: Hypersensitivity pneumonitis probably caused by cyclosporine. A case report. Respir Med 1998, 92:1368-1370.

115. Jiménez-Alvarez L, Arreola JL, Ramírez-Martínez G, et al: The effect of CTLA$4 \mathrm{lg}$, a CD28/B7 antagonist, on the lung inflammation and T cell subset profile during murine hypersensitivity pneumonitis. Exp Mol Pathol 2011, 91:718-22.

116. Casilli F, Bianchini A, Gloaguen I, et al: Inhibition of interleukin-8 [CXCL8/IL8] responses by repertaxin, a new inhibitor of the chemokine receptors CXCR1 and CXCR2. Biochem Pharmacol 2005, 69:385-394.

117. Zarbock A, Allegretti M, Ley K: Therapeutic inhibition of CXCR2 by Reparixin attenuates acute lung injury in mice. Br J Pharmacol 2008, 155:357-364.

doi:10.1186/2045-7022-3-5

Cite this article as: Agache and Rogozea: Management of hypersensivity pneumonitis. Clinical and Translational Allergy 2013 3:5.

\section{Submit your next manuscript to BioMed Central and take full advantage of:}

- Convenient online submission

- Thorough peer review

- No space constraints or color figure charges

- Immediate publication on acceptance

- Inclusion in PubMed, CAS, Scopus and Google Scholar

- Research which is freely available for redistribution

Submit your manuscript at www.biomedcentral.com/submit
C Biomed Central 